\title{
Nanosheet-Assembled ZnO Microflower Photocatalysts
}

\author{
Siwen Zhang, Bosi Yin, Yang Jiao, Yang Liu, Fengyu Qu, and Xiang Wu \\ Key Laboratory for Photonic and Electronic Bandgap Materials, Ministry of Education, Harbin Normal University, \\ Harbin 150025, China \\ Correspondence should be addressed to Xiang Wu; wuxiang05@gmail.com
}

Received 9 January 2014; Accepted 16 January 2014; Published 13 May 2014

Academic Editor: Chuanfei Guo

Copyright (c) 2014 Siwen Zhang et al. This is an open access article distributed under the Creative Commons Attribution License, which permits unrestricted use, distribution, and reproduction in any medium, provided the original work is properly cited.

\begin{abstract}
Large scale $\mathrm{ZnO}$ microflowers assembled by numerous nanosheets are synthesized through a facile and effective hydrothermal route. The structure and morphology of the resultant products are characterized by X-ray diffraction (XRD) and scanning electron microscope (SEM). Photocatalytic properties of the as-synthesized products are also investigated. The results demonstrate that eosin red aqueous solution can be degraded over $97 \%$ after 110 min under UV light irradiation. In addition, methyl orange (MO) and Congo red (CR) aqueous solution degradation experiments also are conducted in the same condition, respectively. It showed that nanosheet-assembled $\mathrm{ZnO}$ microflowers represent high photocatalytic activities with a degradation efficiency of $91 \%$ for $\mathrm{CR}$ with $90 \mathrm{~min}$ of irradiation and $90 \%$ for $\mathrm{MO}$ with $60 \mathrm{~min}$ of irradiation. The reported $\mathrm{ZnO}$ products may be promising candidates as the photocatalysts in waste water treatment.
\end{abstract}

\section{Introduction}

In recent years, a variety of $\mathrm{ZnO}$ micro/nanostructures have been reported, such as nanowires, nanobelts, nanospring, nanotubes, and hierarchical structures [1-5]. It was believed that these structures may possess unique physical and chemical properties different from their bulk counterpart to meet specific device fabrication demand [6,7]. Among the $\mathrm{ZnO}$ nanostructures reported previously, two-dimensional (2D) nanostructures (such as nanosheets and nanowalls) have attracted more interests due to their unique spatial architecture and large aspect ratio, demonstrating some potential applications in photocatalyst and supercapacitor [8-10]. In literature, Lei et al. synthesized $\mathrm{ZnO}$ nanosheets on the zinc substrate by a hydrothermal method and studied their optical properties [5]. Qiu et al. reported porous $\mathrm{ZnO}$ nanoplate electrodes for dye sensitized solar cells [11]. Kim and coworkers successfully fabricated $\mathrm{ZnO}$ nanowall networks on $\mathrm{GaN} /$ sapphire substrate and investigated their optical properties [12]. Synthesis of porous $\mathrm{ZnO}$ nanoplates by a facile microwave approach has also been reported, as discussed by Jing and Zhan [13].

At present, environment pollution is one of the most serious problems people facing. Therefore it is an urgent task to eliminate the pollutants from water and air. As an important wide bandgap semiconductor material, $\mathrm{ZnO}$ nanostructures may become excellent photocatalyst candidate for photodegradation of the organic dyes molecules due to their low cost, nontoxicity, and high photoactivity [14-16]. The photocatalytic properties of hierarchical $\mathrm{ZnO}$ microflowers and $\mathrm{Ag}_{2} \mathrm{O} / \mathrm{ZnO}$ microflowers have been investigated, as discussed elsewhere [17-19]. In this paper, we used a facile hydrothermal route to synthesize $\mathrm{ZnO}$ nanosheets at mild temperature. The photocatalytic efficiencies of the synthesized product were evaluated by photodegradation of methyl orange, eosin red, and Congo red under UV irradiation, showing that the as-synthesized $\mathrm{ZnO}$ nanosheets possess high photocatalytic activity in the degradation of organic dyes.

\section{Experimental Details}

In this experiment, all reagents were of analytical grade and used without further purification. A typical experiment procedure is described as follows: $1.32 \mathrm{~g} \mathrm{Zn}\left(\mathrm{CH}_{3} \mathrm{COO}\right)_{2}$ and $1.68 \mathrm{~g} \mathrm{NaHCO}_{3}$ were added into $20 \mathrm{~mL}$ distilled water, respectively. Then $0.1 \mathrm{~g}$ sodium dodecyl sulfate (SDS) was added into the $\mathrm{Zn}\left(\mathrm{CH}_{3} \mathrm{COO}\right)_{2}$ mixture solution. Then the above solution was added to $\mathrm{NaHCO}_{3}$ solution under vigorous 


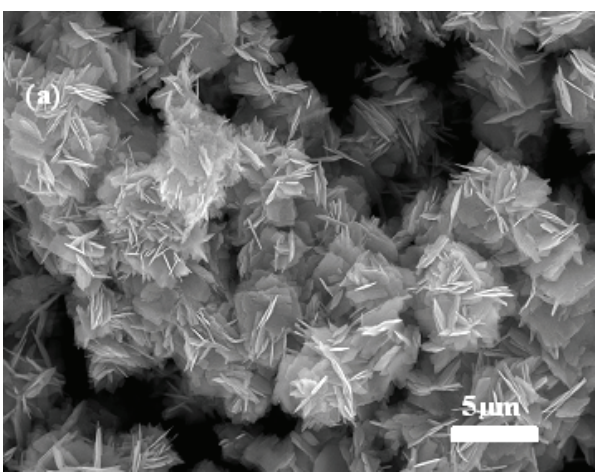

(a)

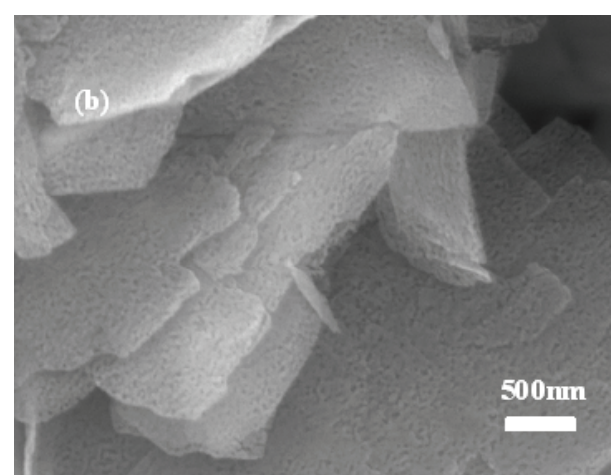

(b)

FIGURE 1: Morphologies of the as-synthesized ZnO microflowers. (a) Low magnification SEM images. (b) High magnification SEM images.

stirring. After stirring for $1 \mathrm{~h}$, the suspension was transferred into a PTFE-line autoclave with a volume of $100 \mathrm{~mL}$. The autoclave was sealed and kept at $140^{\circ} \mathrm{C}$ for $12 \mathrm{~h}$. After that, the solution was cooled down to room temperature. The precipitate was then washed several times with deionized water and ethanol, respectively. Finally the product was dried in a chamber at $60^{\circ} \mathrm{C}$ for $12 \mathrm{~h}$ and annealed in a muffle kiln at $280^{\circ} \mathrm{C}$ for $2 \mathrm{~h}$.

The obtained product was characterized by scanning electron microscope (SEM, Hitachi-4800). The phases of the asobtained products were identified by means of X-ray powder diffraction (XRD, Rigaku Dmax-2600/pc, Cu K $\alpha$ radiation, $\lambda$ $=0.1542 \mathrm{~nm}, 40 \mathrm{KV}, 100 \mathrm{~mA}$ ). The photocatalytic degradation efficiency was analyzed by monitoring dye decolorization at the maximum absorption wavelength, using a UV/Vis Spectrometer (Shimazu UV-2550).

\section{Results and Discussion}

Morphologies of the as-synthesized product were observed first by SEM. Figure 1(a) represents a typical low magnification SEM image, demonstrating large quantities of flower-like structures. Further observation finds that these microflowers consisted of numerous porous sheets with an average thickness of about tens of nanometers, as shown in Figure 1(b). XRD pattern of the as-obtained products was shown in Figure 2. All of the diffraction peaks can be straightforwardly indexed to hexagonal wurtzite $\mathrm{ZnO}$ structure, which are in accordance with the standard PDF card (JCPDS: 36-1451). No peaks of other phases were detected, indicating high purity of the as-synthesized product.

To investigate the effect of the growth parameters on the morphology of $\mathrm{ZnO}$ nanosheets, a series of comparison experiments was conducted. First, Figures 3(a) and 3(b) show SEM images of the product before calcination, finding that no pores appear and showing that the annealing treatment plays a very important role in the formation of pores. Subsequently, we will use $\mathrm{Na}_{2} \mathrm{CO}_{3}$ instead of $\mathrm{NaHCO}_{3}$; it is obvious that the sheet-like $\mathrm{ZnO}$ nanostructures become coarse, as shown in Figures 3(c) and 3(d). Based on the above experimental

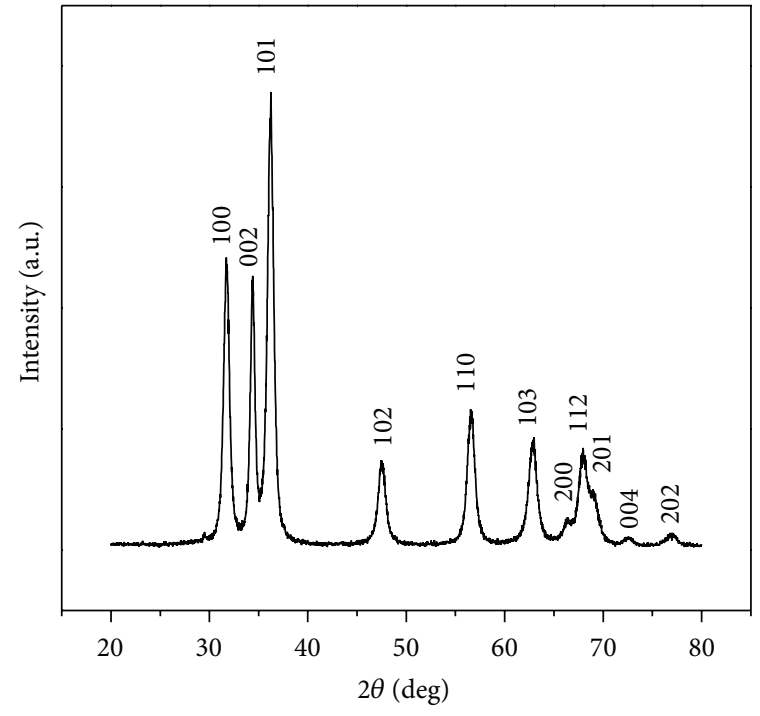

FIGURE 2: XRD pattern of the as-synthesized samples.

results, a possible growth mechanism can be proposed as follows:

$$
\begin{gathered}
\mathrm{Zn}(\mathrm{Ac}) 2 \longrightarrow \mathrm{Zn}^{2+}+2 \mathrm{Ac}^{-} \\
\mathrm{Ac}^{-}+\mathrm{H}_{2} \mathrm{O} \longrightarrow \mathrm{HAc}+\mathrm{OH}^{-} \\
\mathrm{HCO}^{3-}+\mathrm{OH}^{-} \longrightarrow \mathrm{CO}_{3}{ }^{2-}+\mathrm{H}_{2} \mathrm{O} \\
\mathrm{Zn}^{2+}+\mathrm{CO}_{3}{ }^{2-} \longrightarrow \mathrm{ZnCO}_{3} \longrightarrow \mathrm{ZnO}+\mathrm{CO}_{2}
\end{gathered}
$$

In the initial stage, $\mathrm{Zn}^{2+}$ and $\mathrm{CO}_{3}{ }^{-}$react with each other to form $\mathrm{ZnCO}_{3}$ small particles. These particles have a tendency to aggregate due to large surface energy [20]. Surface energy is substantially reduced when the neighboring nanoparticles are grown. With the crystal growth continuing, each nanoparticle in the aggregates or nanosheet acts as a nucleus for further growth. These growth processes are not only related to the anisotropic $\mathrm{ZnO}$ crystal structure, but also related to the involved reaction conditions. The growth habit 


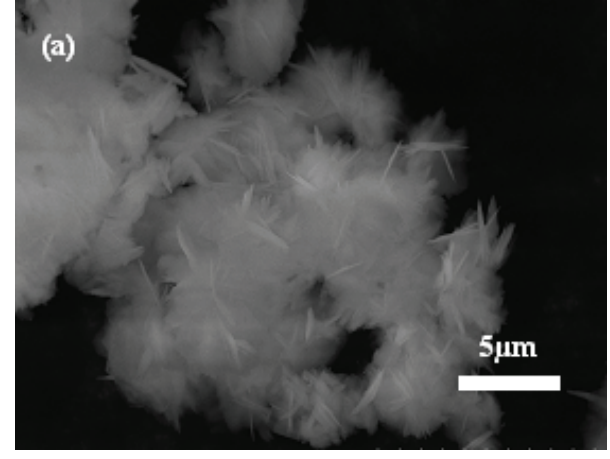

(a)

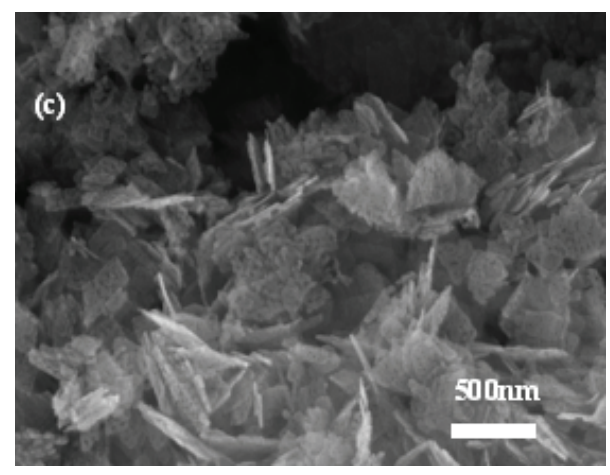

(c)

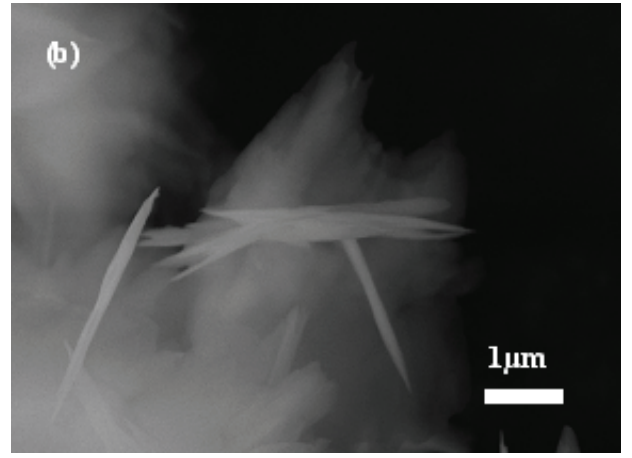

(b)

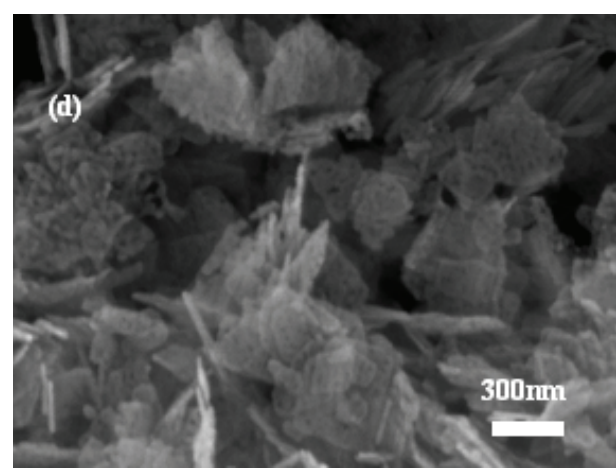

(d)

FigURE 3: (a) and (b) SEM images of the product before calcination. (c) and (d) SEM images of the product using $\mathrm{Na}_{2} \mathrm{CO}_{3}$ instead of $\mathrm{NaHCO}_{3}$.
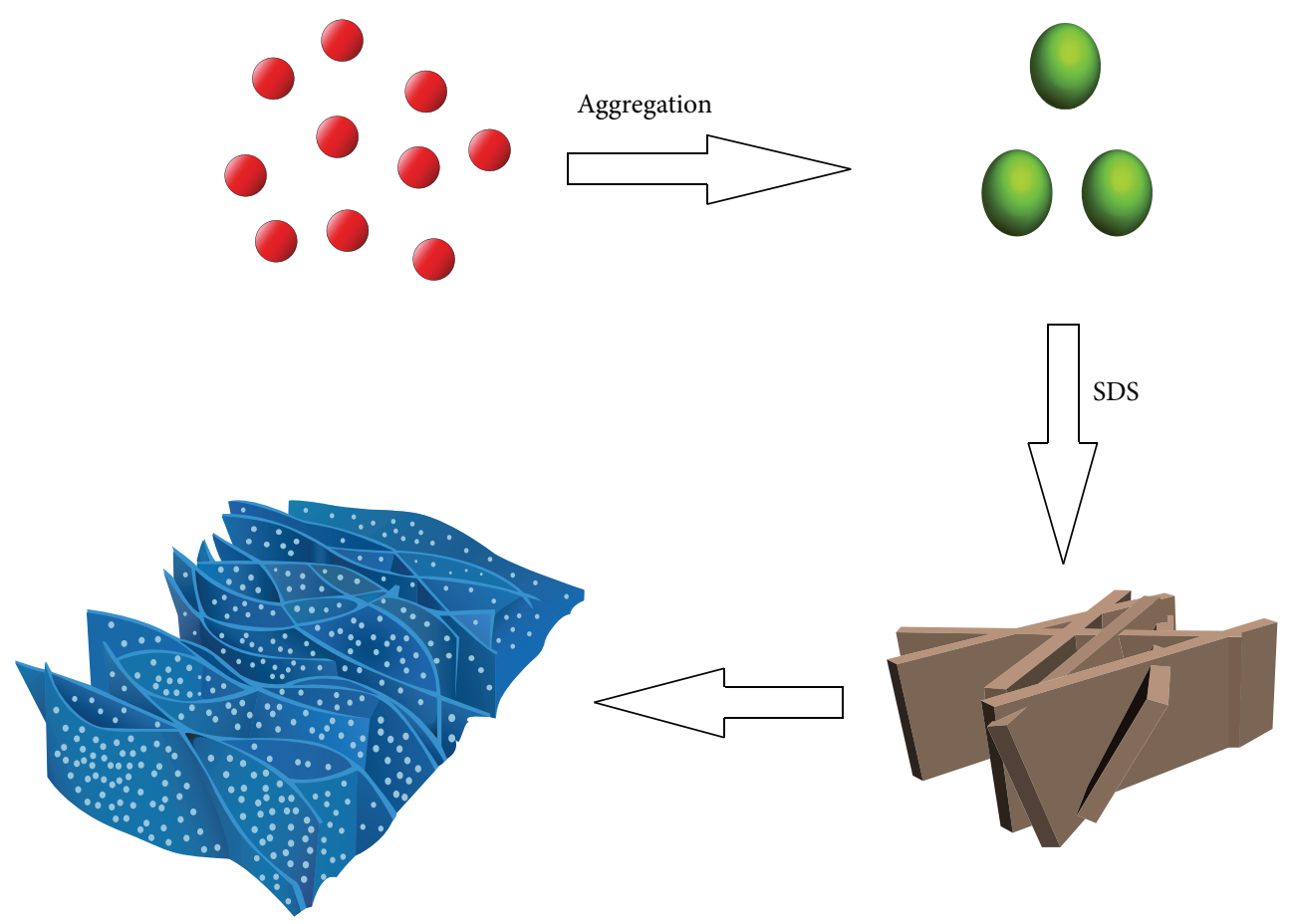

FIGURE 4: Growth schematic of the as-synthesized $\mathrm{ZnO}$ microflowers. 


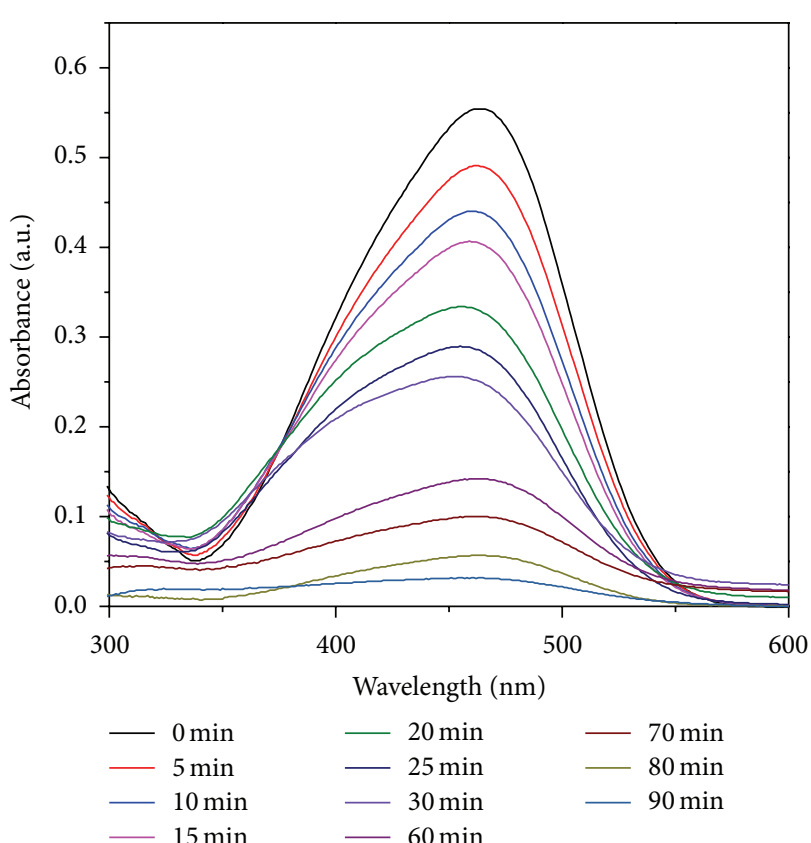

(a)

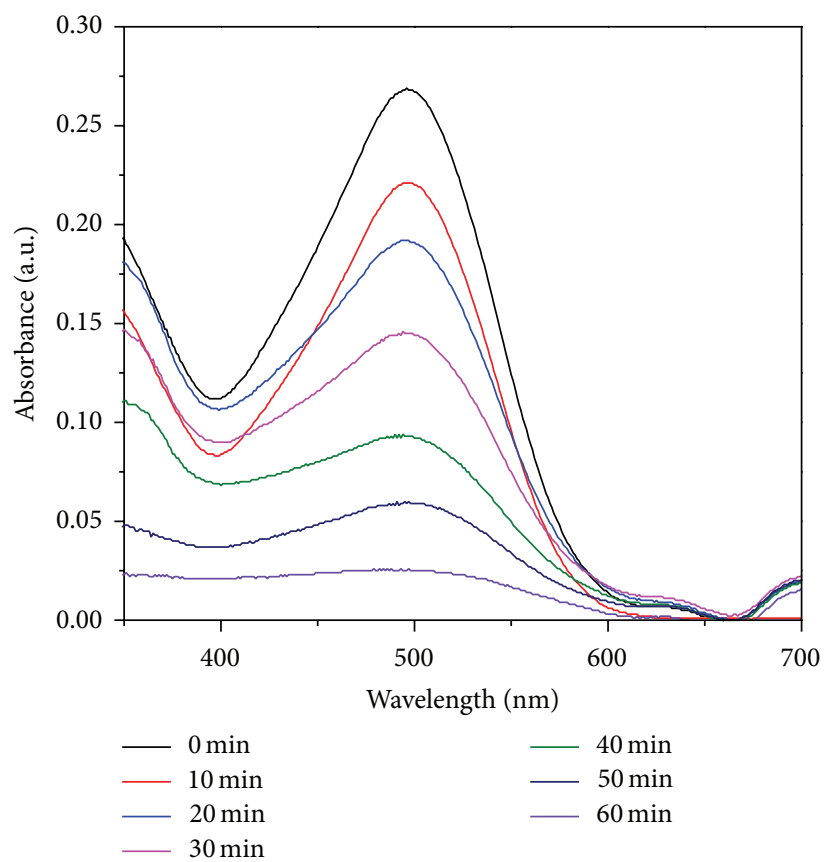

(c)

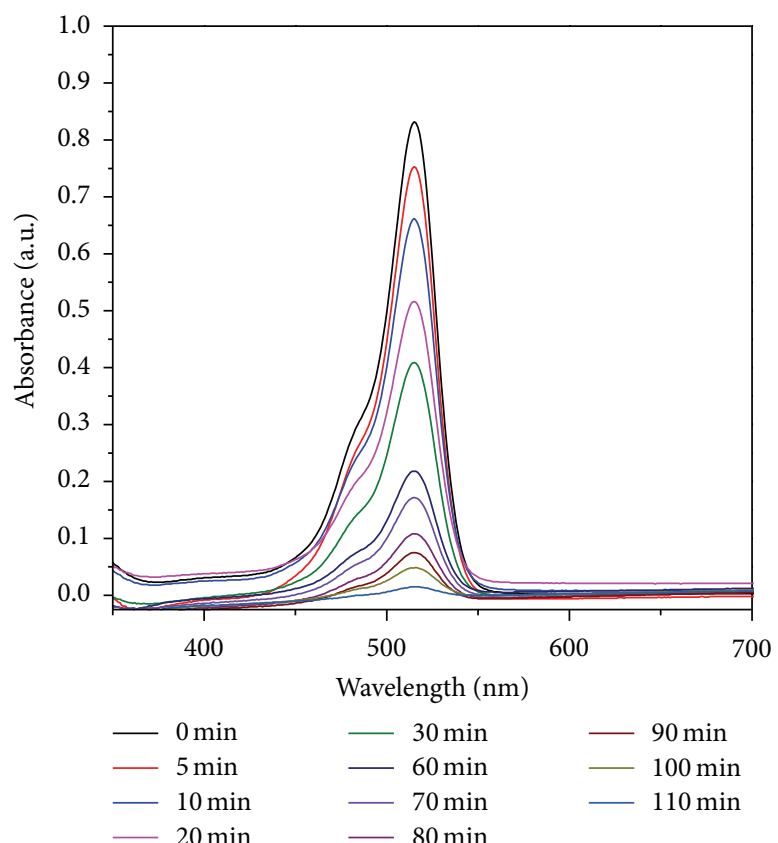

(b)

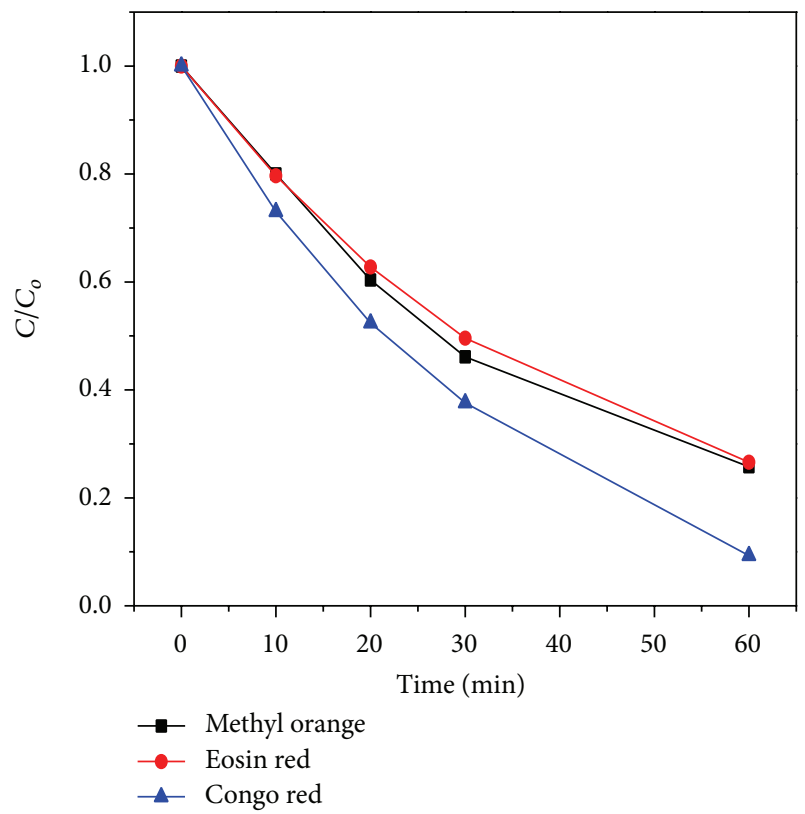

(d)

FIGURE 5: Variations of adsorption spectra of aqueous (a) MO, (b) eosin red, and (c) CR solution in the presence of porous $\mathrm{ZnO}$ nanosheets; (d) degradation rate curves from different dyes at the same time, respectively. 
of $\mathrm{ZnO}$ crystals can control the $\mathrm{ZnO}$ crystals to grow into the nanosheets. SDS serves as a surfactant to induce $\mathrm{ZnCO}_{3}$ nanoparticles into the nanosheets. The $\mathrm{ZnCO}_{3}$ nanosheets precursor is then calcined at $280^{\circ} \mathrm{C}$ in air for $2 \mathrm{~h}$. It is found clearly that the as-synthesized product still keeps nanosheets structure, and the nanosheets possess porous structures, which may be attributed to the overflowing of SDS and $\mathrm{CO}_{2}$ during the calcination process, which is consistent with the previous report [21, 22]. Figure 4 shows a possible growth schematic of the as-synthesized porous $\mathrm{ZnO}$ nanosheets.

In order to study the photocatalytic activities of $\mathrm{ZnO}$ nanostructures with different dye molecules, the photocatalytic degradation experiments of $\mathrm{MO}$, eosin red, and $\mathrm{CR}$ were conducted. Figure 5(a) shows the adsorption spectra of $\mathrm{MO}$ solution in the presence of porous $\mathrm{ZnO}$ nanosheets under UV light at different time interval. The main absorption peak of $\mathrm{MO}$ centered at $465 \mathrm{~nm}$. When the illumination time was extended to $90 \mathrm{~min}$, the absorption peak diminished gradually and the photodegradation ratios of $\mathrm{MO}$ were up to 90\%. Figure 5(b) shows UV adsorption spectra of eosin red with the absorption peak of $517 \mathrm{~nm}$; nearly $97 \%$ of eosin red molecules were decomposed in $110 \mathrm{~min}$. Figure 5(c) shows the absorption spectra of CR solution in the presence of $\mathrm{ZnO}$ microflowers under UV light; the main absorption peak of CR centered at $495 \mathrm{~nm}$. When the light was turned on, the main peaks decreased continuously with increased irradiation time, indicating that the CR solution was decomposed in the present system. When the illumination time was extended to $60 \mathrm{~min}$, the color of the CR solution almost disappeared, and the absorption peak corresponding to CR at $495 \mathrm{~nm}$ diminished tremendously with the photocatalytic degradation rate of $\mathrm{CR}$ of $91 \%$. Porous $\mathrm{ZnO}$ nanosheets are the optimal catalysts to degrade CR than the other two dyes. In order to illustrate to which type of dye molecule $\mathrm{ZnO}$ nanosheets are highly selective, we take the same $60 \mathrm{~min}$ to compare the degradation efficiency of different dyes. The results show the order of degradation rate is eosin red (73\%) $<$ MO $(75 \%)<$ CR $(91 \%)$. It indicates that CR degradation efficiency is better than $\mathrm{MO}$ and eosin red as shown in Figure 5(d).

\section{Conclusion}

Nanosheet-assembled $\mathrm{ZnO}$ microflowers with high yield have been successfully obtained by a simple hydrothermal approach. The possible growth mechanism of the $\mathrm{ZnO}$ microflowers is proposed based on the experimental results. The photocatalytic degradation experiments showed that $\mathrm{ZnO}$ microflowers possess a high photocatalytic activity for the degradation of Congo red dyes with the degradation rate being $97 \%$ in $60 \mathrm{~min}$. It is expected that such $\mathrm{ZnO}$ microflowers may have applications in eliminating organic pollutant in waste water.

\section{Conflict of Interests}

The authors declare that there is no conflict of interests regarding the publication of this paper.

\section{Acknowledgment}

This work was supported by Program for New Century Excellent Talents in Heilongjiang Provincial University (1252NCET-018).

\section{References}

[1] X. Wu, P. Jiang, Y. Ding, W. Cai, S.-S. Xie, and Z. L. Wang, "Mismatch strain induced formation of $\mathrm{ZnO} / \mathrm{ZnS}$ heterostructured rings," Advanced Materials, vol. 19, no. 17, pp. 2319-2323, 2007.

[2] X. Wu, W. Cai, and F.-Y. Qu, "Spontaneous formation of single crystal ZnO nanohelices," Chinese Physics B, vol. 18, no. 4, pp. 1669-1673, 2009.

[3] X. Wu, F. Y. Qu, X. Zhang, W. Cai, and G. Z. Shen, "Fabrication of $\mathrm{ZnO}$ ring-like nanostructures at a moderate temperature via a thermal evaporation process," Journal of Alloys and Compounds, vol. 486, no. 1-2, pp. L13-L16, 2009.

[4] L. Vayssieres, K. Keis, A. Hagfeldt, and S.-E. Lindquist, “Threedimensional array of highly oriented crystalline $\mathrm{ZnO}$ microtubes," Chemistry of Materials, vol. 13, no. 12, pp. 4395-4398, 2001.

[5] Y. Lei, F. Y. Qu, and X. Wu, "Assembling $\mathrm{ZnO}$ nanorods into microflowers through a facile solution strategy: morphology control and cathodoluminescence properties," Nano-Micro Letters, vol. 4, no. 1, pp. 45-51, 2012.

[6] Y. P. Fang, X. G. Wen, S. H. Yang et al., "Hydrothermal synthesis and optical properties of $\mathrm{ZnO}$ nanostructured films directly grown from/on zinc substrates," Journal of Sol-Gel Science and Technology, vol. 36, no. 2, pp. 227-234, 2005.

[7] H. W. Suh, G. Y. Kim, Y. S. Jung, W.-K. Choi, and D. Byun, "Growth and properties of $\mathrm{ZnO}$ nanoblade and nanoflower prepared by ultrasonic pyrolysis," Journal of Applied Physics, vol. 97, no. 4, Article ID 044305, 2005.

[8] J. Wang, F. Y. Qu, and X. Wu, "Synthesis of Ultra-Thin ZnO nanosheets: photocatalytic and superhydrophilic properties," Science of Advanced Materials, vol. 5, pp. 1052-1059, 2013.

[9] C. F. Guo, Y. S. Wang, and Q. Liu, "Ultrathin $\mathrm{ZnO}$ nanostructures synthesized by thermal oxidation of hexagonal $\mathrm{Zn}$ micro/nanostructures," Journal of Nanoscience and Nanotechnology, vol. 10, no. 11, pp. 7167-7170, 2010.

[10] S. W. Liu, C. Li, J. G. Yu, and Q. J. Xiang, "Improved visiblelight photocatalytic activity of porous carbon self-doped $\mathrm{ZnO}$ nanosheet-assembled flowers," CrystEngComm, vol. 13, no. 7, pp. 2533-2541, 2011.

[11] Y. C. Qiu, W. Chen, and S. H. Yang, "Facile hydrothermal preparation of hierarchically assembled, porous single-crystalline $\mathrm{ZnO}$ nanoplates and their application in dye-sensitized solar cells," Journal of Materials Chemistry, vol. 20, no. 5, pp. 10011006, 2010.

[12] S.-W. Kim, H.-K. Park, M.-S. Yi et al., "Epitaxial growth of $\mathrm{ZnO}$ nanowall networks on GaN/sapphire substrates," Applied Physics Letters, vol. 90, no. 3, Article ID 033107, 2007.

[13] Z. H. Jing and J. H. Zhan, "Fabrication and gas-sensing properties of porous $\mathrm{ZnO}$ nanoplates," Advanced Materials, vol. 20, no. 23, pp. 4547-4551, 2008.

[14] B. Liu, J. Xu, S. H. Ran, Z. R. Wang, D. Chen, and G. Z. Shen, "High-performance photodetectors, photocatalysts, and gas sensors based on polyol reflux synthesized porous $\mathrm{ZnO}$ nanosheets," CrystEngComm, no. 14, pp. 4582-4588, 2012. 
[15] J. F. Li, G. Z. Lu, Y. Q. Wang, Y. Guo, and Y. L. Guo, "A high activity photocatalyst of hierarchical 3D flowerlike $\mathrm{ZnO}$ microspheres:synthesis, characterization and catalytic activity," Journal of Colloid Interface Science, vol. 377, no. 1, pp. 191-196, 2012.

[16] M. Rajneesh, K. Karthikeyan, and S. J. Kim, "Diameter dependent photocatalytic activity of $\mathrm{ZnO}$ nanowires grown by vapor transport technique," Chemical Physics Letters, vol. 539-540, pp. 83-88, 2012.

[17] J. Wang, F. Y. Qu, and X. Wu, "High selective photocatalytic properties of three dimensional hierarchical $\mathrm{ZnO}$ microflowers," Materials Express, vol. 3, pp. 256-264, 2013.

[18] J. Wang, F. Y. Qu, and X. Wu, "Photocatalytic degradation of organic dyes with hierarchical $\mathrm{Ag}_{2} \mathrm{O} / \mathrm{ZnO}$ heterostructures," Science of Advanced Materials, vol. 5, no. 10, pp. 1364-1371, 2013.

[19] J. Wang, Y. Liu, Y. Jiao, F. Y. Qu, Q. Z. Pan, and X. Wu, "Hybrid $\mathrm{Ag}_{2} \mathrm{O} / \mathrm{ZnO}$ heterostructures," Journal of Nanomaterials, vol. 2013, Article ID 684797, p. 5, 2013.

[20] H. X. Li, M. X. Xia, G. Z. Dai et al., "Growth of oriented zinc oxide nanowire array into novel hierarchical structures in aqueous solutions," Journal of Physical Chemistry C, vol. 112, no. 45, pp. 17546-17553, 2008.

[21] J. B. Lian, Z. M. Ding, F.-L. Kwong, and D. H. L. Ng, “Templatefree hydrothermal synthesis of hexagonal $\mathrm{ZnO}$ micro-cups and micro-rings assembled by nanoparticles," CrystEngComm, vol. 13, no. 15, pp. 4820-4822, 2011.

[22] J. R. Huang, Y. J. Wu, C. P. Gu, M. H. Zhai, Y. Sun, and J. Liu, "Fabrication and gas-sensing properties of hierarchically porous $\mathrm{ZnO}$ architectures," Sensors and Actuators, B: Chemical, vol. 155, no. 1, pp. 126-133, 2011. 

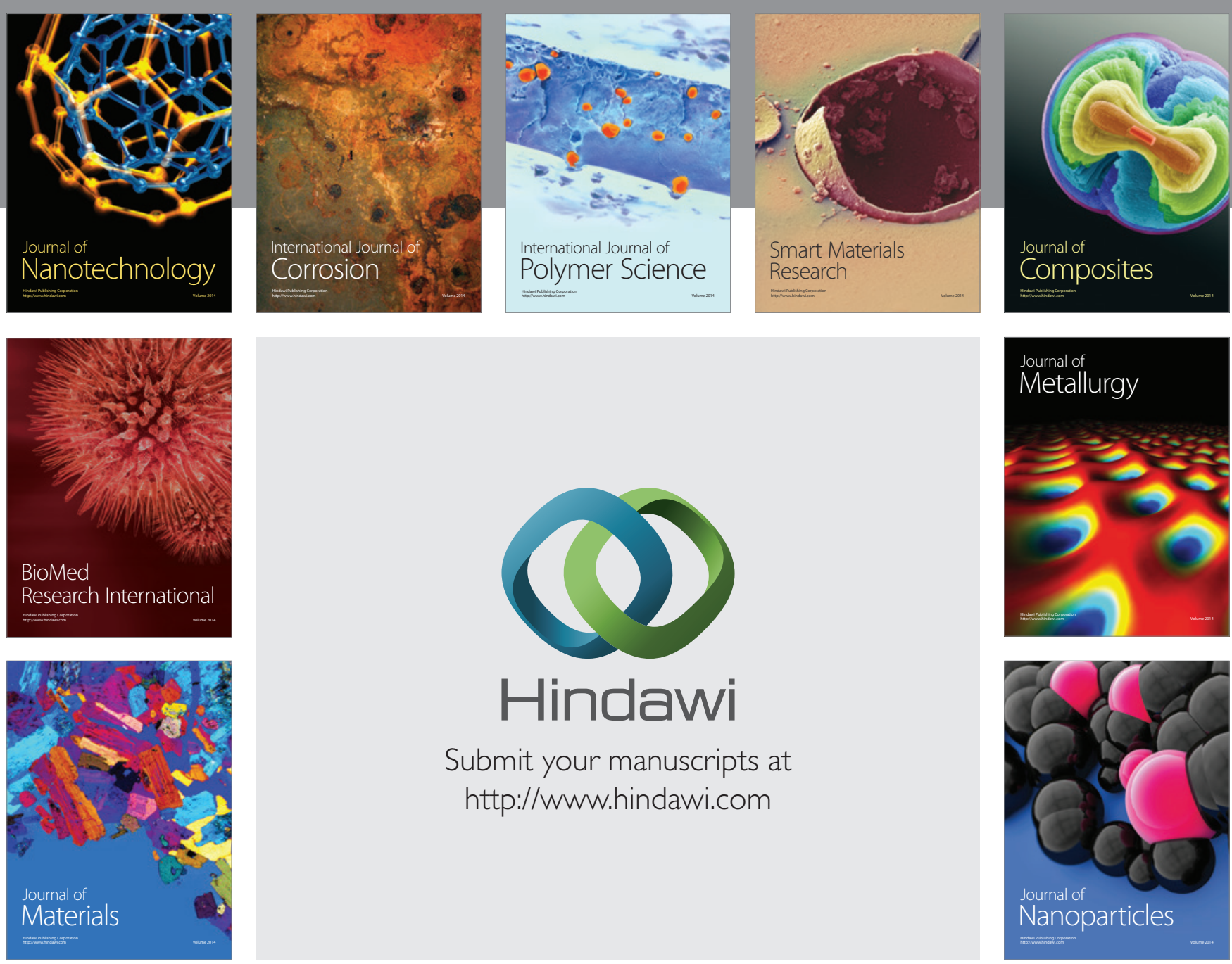

Submit your manuscripts at http://www.hindawi.com
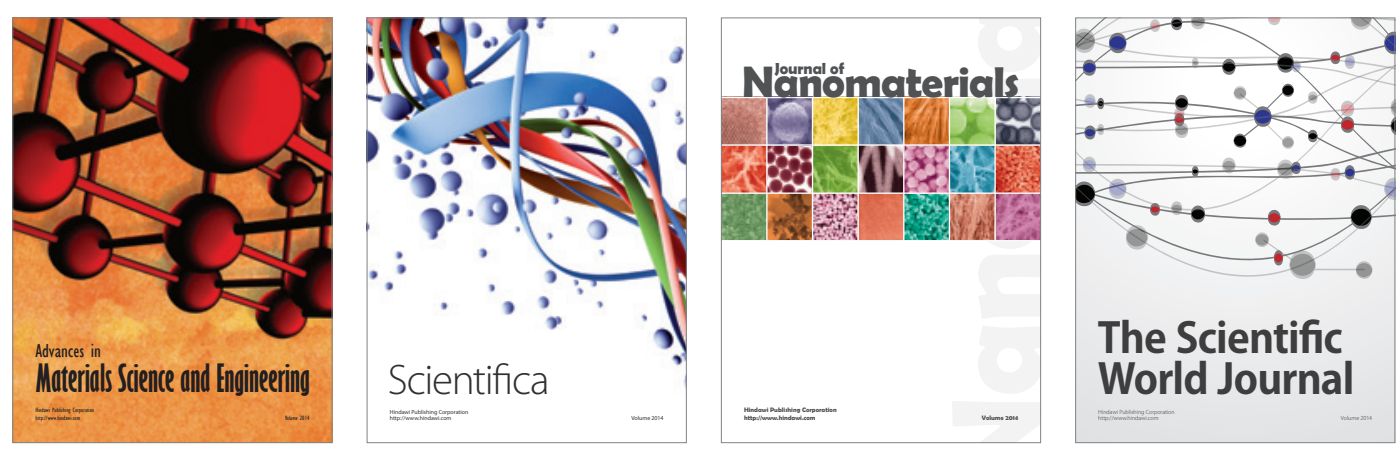

\section{The Scientific World Journal}
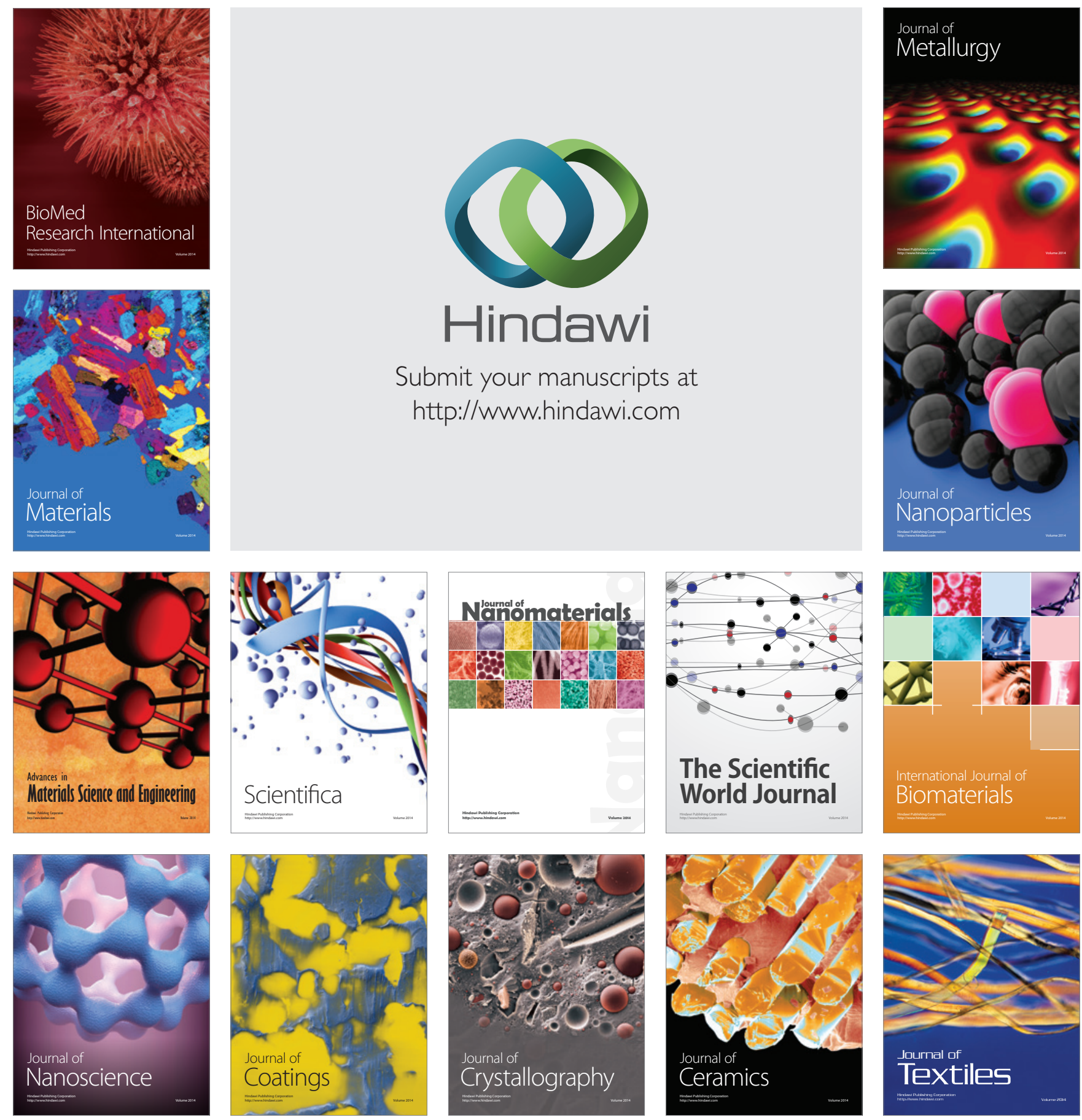